\title{
Caterpillar Light Truck Clean Diesel Program
}

\author{
Robert L. Miller, Kevin P. Duffy and Michael A. Flinn
} Caterpillar, Inc.

Steve A. Faulkner and Mike A. Graham Perkins Technology Consultancy

Permission is hereby granted for a copyright release fee of $\$ 300$ per paper. An invoice will follow under separate cover. Please be sure to include the following credit statement with these papers:

"(C) Society of Automotive Engineers, Inc. The following papers are published on this web-site with permission from the Society of Automotive Engineers, Inc. As a user of this web-site, you are permitted to view these papers on-line, download the PDF file and to print a copy at no cost for your use only. Dowloaded PDF files and printouts of SAE papers

contained on this web-site may not be copied or distributed to others or for the use of others." 
The appearance of this ISSN code at the bottom of this page indicates SAE's consent that copies of the paper may be made for personal or internal use of specific clients. This consent is given on the condition, however, that the copier pay a $\$ 7.00$ per article copy fee through the Copyright Clearance Center, Inc. Operations Center, 222 Rosewood Drive, Danvers, MA 01923 for copying beyond that permitted by Sections 107 or 108 of the U.S. Copyright Law. This consent does not extend to other kinds of copying such as copying for general distribution, for advertising or promotional purposes, for creating new collective works, or for resale.

SAE routinely stocks printed papers for a period of three years following date of publication. Direct your orders to SAE Customer Sales and Satisfaction Department.

Quantity reprint rates can be obtained from the Customer Sales and Satisfaction Department.

To request permission to reprint a technical paper or permission to use copyrighted SAE publications in other works, contact the SAE Publications Group.

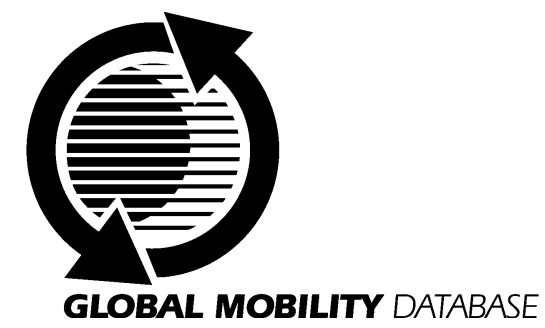

All SAE papers, standards, and selected books are abstracted and indexed in the Global Mobility Database

No part of this publication may be reproduced in any form, in an electronic retrieval system or otherwise, without the prior written permission of the publisher.

\section{ISSN 0148-7191}

Copyright 1999 Society of Automotive Engineers, Inc.

Positions and opinions advanced in this paper are those of the author(s) and not necessarily those of SAE. The author is solely responsible for the content of the paper. A process is available by which discussions will be printed with the paper if it is published in SAE Transactions. For permission to publish this paper in full or in part, contact the SAE Publications Group.

Persons wishing to submit papers to be considered for presentation or publication through SAE should send the manuscript or a 300 word abstract of a proposed manuscript to: Secretary, Engineering Meetings Board, SAE.

\section{Printed in USA}




\title{
Caterpillar Light Truck Clean Diesel Program
}

\author{
Robert L. Miller, Kevin P. Duffy and Michael A. Flinn \\ Caterpillar, Inc.
}

\author{
Steve A. Faulkner and Mike A. Graham \\ Perkins Technology Consultancy
}

Copyright (C) 1999 Society of Automotive Engineers, Inc.

\begin{abstract}
In 1998, light trucks accounted for over $48 \%$ of new vehicle sales in the U.S. and well over half the new Light Duty vehicle fuel consumption. The Light Truck Clean Diesel (LTCD) program seeks to introduce large numbers of advanced technology diesel engines in light-duty trucks that would improve their fuel economy $(\mathrm{mpg})$ by at least $50 \%$ and reduce our nation's dependence on foreign oil. Incorporating diesel engines in this application represents a high-risk technical and economic challenge. To meet the challenge, a government-industry partnership (Department of Energy, diesel engine manufacturers, and the automotive original equipment manufacturers) is applying joint resources to meet specific goals that will provide benefits to the nation. [1]

Caterpillar initially teamed with Ford Motor Company on a 5 year program (1997-2002) to develop prototype vehicles that demonstrate a $50 \%$ fuel economy improvement over the current 1997 gasoline powered light truck vehicle in this class while complying with EPA's Tier II emissions regulations. The light truck vehicle selected for the demonstration is a 1999 Ford F150 SuperCab. To meet the goals of the program, the $4.6 \mathrm{~L} \mathrm{~V}$ 8 gasoline engine in this vehicle will be replaced by an advanced compression ignition direct injection (CIDI) engine. Key elements of the Caterpillar LTCD program plan to develop the advanced CIDI engine are presented in this paper.
\end{abstract}

\section{INTRODUCTION}

Caterpillar Inc.'s Engine Research department is involved in a program to develop technologically advanced prototype engines for the Sport Utility Vehicle (SUV) and Light Truck (LT) vehicle markets. Meeting the objectives of this program, which is co-funded by the Department of Energy's Office of Heavy Vehicle Technologies (DOEOHVT) office, will result in vehicular powerplants capable of delivering significant fuel savings in this fast-growing consumer market.
In 1998, Light Trucks (pickups and sport utility vehicles $<8500 \#$ GVW) comprised over $48 \%$ of new vehicle sales in the U.S. [2] and well over half of the new L.D. vehicle fuel consumption. At the same time, higher technology diesel engines are making dramatic gains in the higher priced fuel markets such as Europe. Automakers and the DOE feel that there is a demand waiting to be satisfied with an advanced diesel engine for LT's and SUV's in the U.S. market. Converting these vehicles to advanced, ultra low emitting diesel engines would improve their tankmiles-per-gallon fuel economy by at least $50 \%$. With a $3 \%$ market penetration, this corresponds to national fuel savings of $0.5 \mathrm{MBPD}$ (million barrels per day), or roughly $30 \%$ of our nation's total Persian Gulf oil import levels.

The challenge in DOE's Light Truck Clean Diesel program is to maintain the inherent fuel economy benefits of the diesel engine powerplant while meeting the stringent gaseous and particulate emissions requirements expected to be defined in EPA legislation. Caterpillar's Light Truck Clean Diesel (LTCD) program goal as stated in the Caterpillar-DOE Cooperative Agreement (DE-FC05-97OR 22605, dated September 8, 1997 ) is to deliver prototype vehicles in 2002 demonstrating a $50 \%$ fuel economy improvement over 1997 gasoline powered vehicles while complying with EPA's Tier II emissions regulations. In the absence of formally established emission standards, the original target emission goals were set at $0.5 \mathrm{~g} / \mathrm{mile} \mathrm{NOx}$ and $0.05 \mathrm{~g} /$ mile particulate matter (PM) over the US FTP-75 transient emissions cycle. Significant emissions reduction technology will be required to meet these emission requirements.

In early 1998, the Caterpillar LTCD team anticipated the Tier II emission standards would be formally set at levels approaching the proposed California LEV 2 (Lower Emission Vehicle) levels of $0.05 \mathrm{~g} / \mathrm{mile}$ NOx and $0.01 \mathrm{~g} /$ mile PM. Due to the significant challenge of meeting these anticipated Tier II emission standards, the scope of the program was redefined to increase funding of aftertreatment development in order to develop emissions reduction technology. Caterpillar and Ford also mutually agreed to reduced Ford's active participation. 


\section{CATERPILLAR'S LTCD PROGRAM}

Caterpillar initially teamed with Ford Motor Company on this 5 year program (1997-2002) to develop prototype vehicles demonstrating the target fuel economy and emissions levels through the use of advanced compression ignition, direct injection (CIDI) technologies. These powerplants will meet the requirements of the program and provide excellent driveability due to the excellent low-end torque characteristics inherent in CIDI engines.

The program (Fig. 1) consists of five primary tasks. 1998 activities focused on tasks $(1.1-1.4)$ which included defining specifications for the technologically advanced vehicle and powertrain, developing parallel technologies necessary to meet the program goals, demonstrating these technologies on mule High Speed Direct Injection (HSDI) engines, and design of the LTCD vehicle engine.

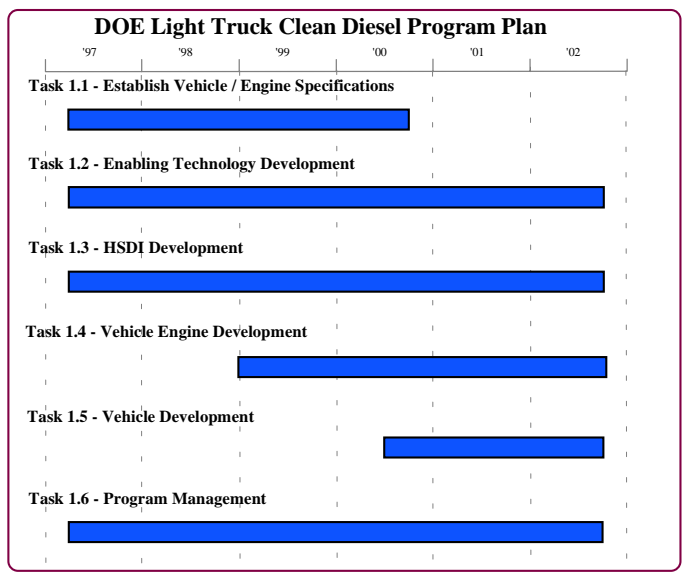

Figure 1. Caterpillar LTCD Program

Each technology will pass through a rigorous downselection process involving assessments against performance, cost and feasibility goals prior to their incorporation into the LTCD demonstration engines.

The development team elected to utilize an existing HSDI engine platform and established a two-phase emissions development program. The Phase 1 program will provide a vehicle demonstration of the original program emission goals of $0.5 \mathrm{~g} / \mathrm{mile} \mathrm{NOx}$ and $0.05 \mathrm{~g} / \mathrm{mile} \mathrm{PM}$ while meeting the $50 \%$ improved fuel economy target. The Phase 2 program will demonstrate the proposed LEV 2 standards $(0.05 \mathrm{~g} / \mathrm{mile} \mathrm{NOx}$ and $0.01 \mathrm{~g} / \mathrm{mile} \mathrm{PM})$ on a HSDI engine operating in a transient emissions test bed while meeting the $50 \%$ improved fuel economy target.

The LTCD focus vehicle (Fig. 2) selected for the Phase 1 demonstration was a 1999 Ford F150 SuperCab. Ford supplied to Caterpillar three of these vehicles to support the LTCD program.

The vehicles were equipped with a $4.6 \mathrm{~L} \mathrm{V-8}$ gasoline engine and a 5 speed manual transmission. A 1998 Ford 150 SuperCab will serve as the baseline vehicle. Performance of the 1999 F150 vehicle equipped with the LTCD HSDI engine will be compared against the 1998 baseline. The development team is scheduled to deliver 3 prototype vehicles in 2002 with CIDI engines exhibiting performance specifications approximating those shown in Fig. 3.

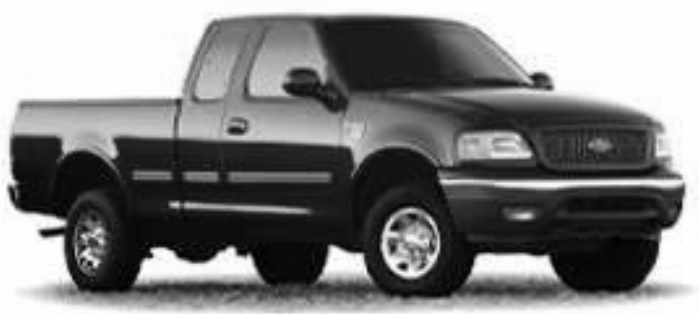

Figure 2. Ford F150 SuperCab [3]

\begin{tabular}{|c|c|c|}
\hline & Baseline & LTCD \\
\hline Vehicle & 1998 F150 & 1999 F150 \\
\hline City Mileage & $15 \mathrm{mpg}$ & $23 \mathrm{mpg}$ \\
\hline Hwy Mileage & $19 \mathrm{mpg}$ & $29 \mathrm{mpg}$ \\
\hline Engine & $4.6 \mathrm{~L} \mathrm{~V}-8$ & $3.0 \mathrm{~L} \mathrm{~V}-6 \mathrm{HSDI}$ \\
\hline Power & $\begin{array}{l}164 \mathrm{~kW} \\
(220 \mathrm{hp})\end{array}$ & $\begin{array}{l}168 \mathrm{~kW} \\
(225 \mathrm{hp})\end{array}$ \\
\hline Torque & $\begin{array}{c}394 \mathrm{Nm} \\
(292 \mathrm{ft}-\mathrm{lb})\end{array}$ & $\begin{array}{l}\text { Up to } 550 \mathrm{Nm} \\
(407 \mathrm{ft}-\mathrm{lb})\end{array}$ \\
\hline Emissions & Tier I & Tier II \\
\hline
\end{tabular}

Figure 3. LTCD Vehicle Specifications

The HSDI platform used for the Phase 1 and Phase 2 demonstrations will be derived from a existing V-6 HSDI engine (Figure 4) originally developed by Perkins-Engine Company, a wholly owned subsidiary of Caterpillar Inc. This prototype engine was developed to demonstrate HSDI technology and the production feasibility for application to the Executive Car, Mini Van, and SUV sectors. [4]

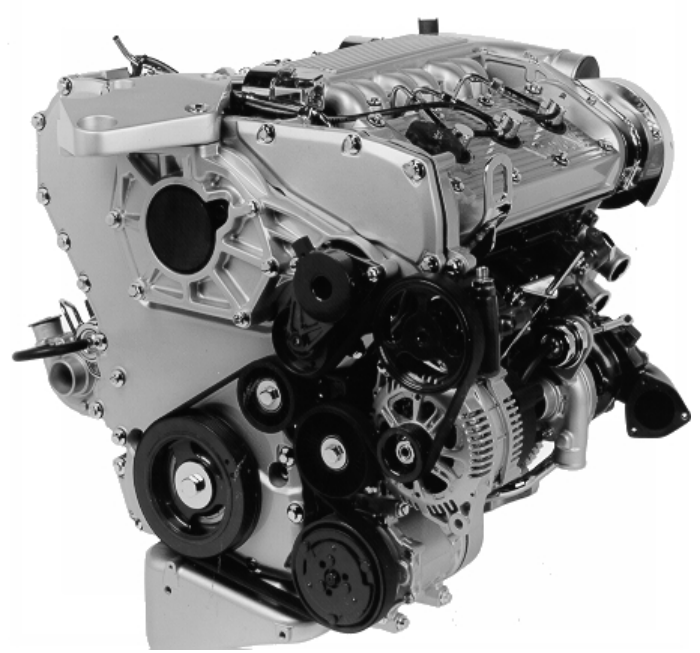

Figure 4. LTCD HSDI Engine Platform 
The technical specifications of the HSDI engine are as follows

- 3.0 Liter, $60^{\circ} \mathrm{V}-6$, even firing

- Rated Power: $127 \mathrm{~kW}$ (170 hp) at 4000-4500 RPM

- Peak Torque: 400 Nm (296 ft-lb) at 2000-2500 RPM

- Euro III Emissions demonstrated in 4050 lbs inertia weight vehicles $(0.4 \mathrm{~g} / \mathrm{km}$ NOx at $0.03 \mathrm{~g} / \mathrm{km}$ particulates)

- 4 valve/cylinder, central vertical injector

- Cast iron block, aluminum cylinder heads

- Twin camshaft/bank, gear linked

- High pressure, electronically controlled fuel injection system (Bosch VP44)

- Twin turbocharger with conventional wastegates and intercooling

- Fully modulated Exhaust Gas Recirculation (EGR), EGR cooling, and oxidation catalyst

The LTCD program has three different classes of engines based on the existing platform. The classes and program applications are described as follows:

ENGINE A - Existing HSDI engine platform for EGR system development and to explore increased power density.

ENGINE B - Upgraded HSDI platform (version A) with the installation of the Caterpillar Hydraulically actuated Electronic Unit Injector (HEUI ${ }^{\mathrm{TM}}$ ) fuel system and a single variable geometry turbocharger (VGT). Power density increased to $47 \mathrm{~kW} /$ liter for initial vehicle development.

ENGINE C - Substantially modified HSDI platform as required to meet the LTCD program requirements for final vehicle demonstration.

\section{TASK DETAIL SUMMARY}

TASK 1.1 - ESTABLISH VEHICLE AND ENGINE SPECIFICATIONS - This task established customer, market, and regulatory expectations for the LTCD vehicles and engine systems that will be used to guide the development phase of the program. These expectations, using information from market research, bench marking and corporate knowledge, were translated into specific vehicle, engine and subsystem objectives in the form of a Quality Function Deployment (QFD). [5]

The QFD process utilized by the LTCD team was divided into four phases:

- Product Planning

- Design Deployment

- Process Planning

- Production Planning
The first step of the product planning process was to identify the customers. The agreed upon customers were the DOE-OHVT, Caterpillar, and the United States Public. Subsequently, a list of customer wants was identified, defined, and ranked. The weighted ranking of the importance of customer requirements, shown in Figure 5, was calculated using a formula developed by the LTCD team. Definitions of these customer requirements are provided in the appendix.

With DOE as the primary client, the LTCD team currently is clearly focused on developing technology to meet the fuel economy and emission program goals. This does not minimize the importance of the other customer requirements such as reliability and manufacturability. The LTCD team recognizes these issues but felt comfortable they could be addressed in the future with the use of the existing HSDI engine platform. The base HSDI engine was initially designed to incorporate the needs of volume production and thus addressed reliability, production and manufacturing issues. This was accomplished using a simultaneous engineering approach with an integrated team, including various engineering specialists covering design, combustion, analysis, value engineering and manufacturing.

Having generated customer requirements, the next stage was to establish the engine design requirements (with measurable targets) to meet them. The team brainstormed a list of 63 targets and established the relationships between each customer requirement and each design requirement to determine the final importance ranking. The relationship between each customer requirement and design requirement was categorized under 'strong', 'medium', and 'weak'. The relationships were weighted 9 for strong, 3 for medium, and 1 for weak.

For each design requirement, the relationship-weighted number was multiplied by the weighted ranking of the customer requirement. The final design importance ranking is the sum of these numbers. The results of the Product Planning ranked the 63 design requirements. Figure 5 shows the ten most important requirements.

These results established the priority of the LTCD team to develop emissions and fuel consumption reduction technology to satisfy the program goals. The next step was to develop measurable targets for each design requirement. For the LTCD vehicle engine, the following preliminary targets were established:

- Power density:

$56 \mathrm{~kW} / \mathrm{liter}$

(75 HP/liter)

- Rated Power (4200 rpm): 168 kW

(225 HP)

- Peak Torque:

$550 \mathrm{Nm}$

(407 ft-lb)

- Peak Cylinder Pressure: 165 bar

- Maximum Exhaust Temp: $850^{\circ} \mathrm{C}$ 


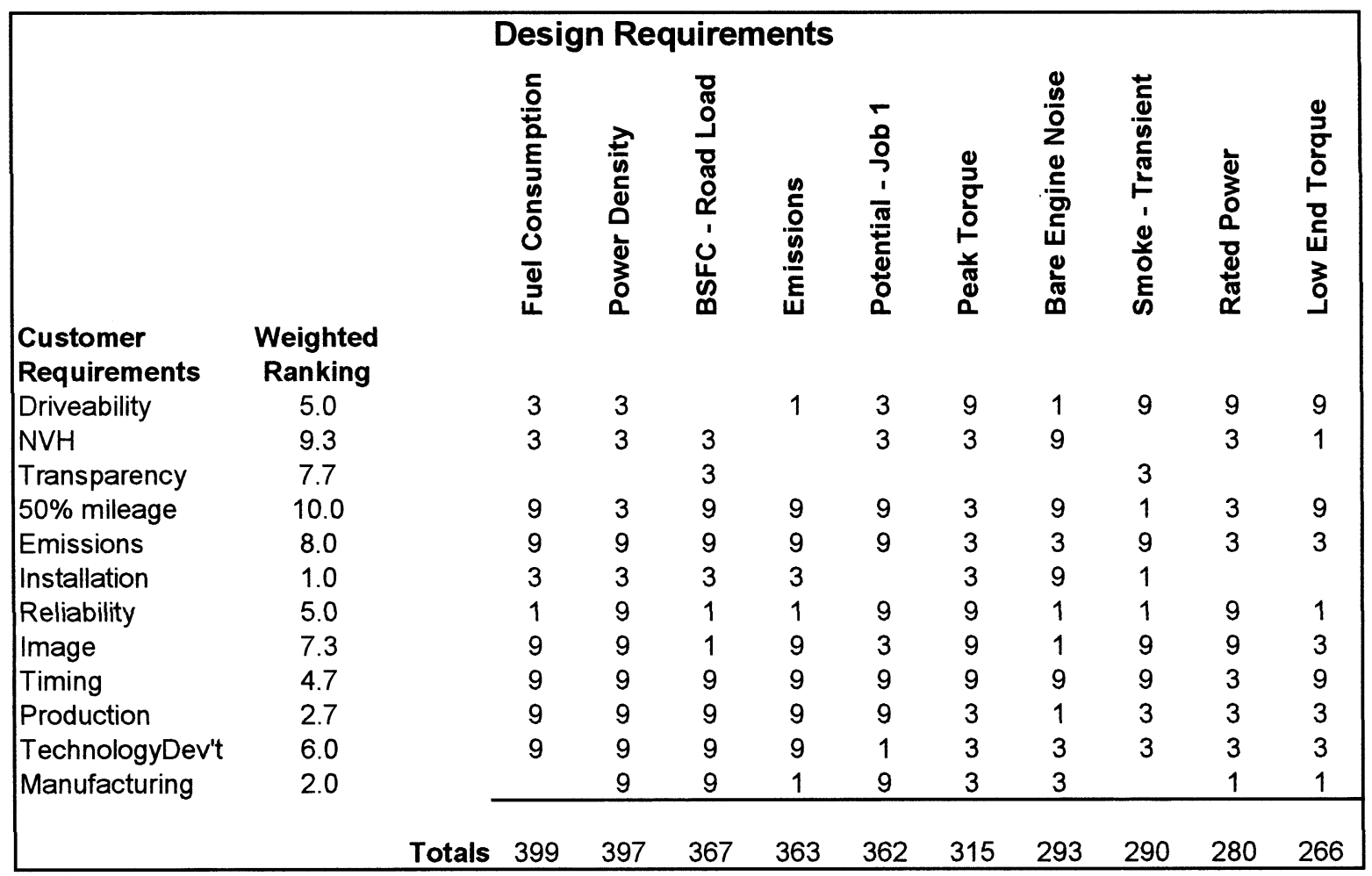

Figure 5. LTCD QFD Results

These targets were established based on results from engine and vehicle simulation models. A powertrain simulation model was constructed based on the F150 SuperCab vehicle equipped with a 5 -speed manual transmission and a HSDI diesel engine rated at $164 \mathrm{~kW}$. Parametric studies were performed to learn proper application of the model for performance calculations including the effects of vehicle weight, shift algorithm, and final drive ratio.

Performance calculations of the F150 with the Base HSDI diesel engine were compared against actual vehicle data. The results, given in Figure 6, show the potential benefits in driveability primarily due to the excellent low-speed torque characteristics of a HSDI diesel powertrain.

\begin{tabular}{|l|c|c|}
\hline & $\begin{array}{c}\text { LTCD F150 } \\
\text { Diesel } \\
\text { (Simulation) }\end{array}$ & $\begin{array}{c}\text { Base F150 } \\
\text { Gasoline } \\
\text { (Test Data) }\end{array}$ \\
\hline $0-60 \mathrm{mph}$ & $10.96 \mathrm{sec}$ & $10.5 \mathrm{sec}$ \\
\hline $1 / 4 \mathrm{mile}$ & $18.2 \mathrm{sec}$ & $18.2 \mathrm{sec}$ \\
\hline $30-50 \mathrm{mph}$ & $4.17 \mathrm{sec}$ & $6.0 \mathrm{sec}$ \\
\hline $50-70 \mathrm{mph}$ & $6.78 \mathrm{sec}$ & $10.6 \mathrm{sec}$ \\
\hline
\end{tabular}

Figure 6. Vehicle Performance Results

Approximately $90 \%$ of the product planning has been completed. The next step will be to start the design deployment (followed by the process planning and the production planning). This phase marks the move from the feasibility study to the concept design stage. Concepts will be developed to the point where a realistic assessment can be made against the design requirements.

As part of the concept design work, a feasibility study was completed to investigate and specify the appropriate HSDI engine configuration for the LTCD vehicle demonstration. The study assumed the eventual engine will be installed in a Ford 150 vehicle, is not constrained in any way by the current HSDI engine specification, and meets the preliminary targets established by the QFD. The results of the study provided the following key recommendations to include in the LTCD vehicle engine:

- Retain the 3 Liter $60^{\circ} \mathrm{V}-6$ configuration.

- An aluminum block structure based on image and technology aspects. Engine structure concepts should be developed to the point where the NVH implications of using aluminum or compacted graphite iron for the cylinder block assembly can be determined.

- Utilize engine and vehicle simulations to determine performance requirements together with the resulting mechanical and thermal loading. Design analysis studies to optimizing the cylinder head structure.

- Develop a inlet port configuration to optimize the appropriate swirl for optimum combustion matching and lowest pumping losses.

- The air system should include one or two variable geometry/nozzle (VGT/VNT) turbochargers for improved low speed driveability and superior emissions. 


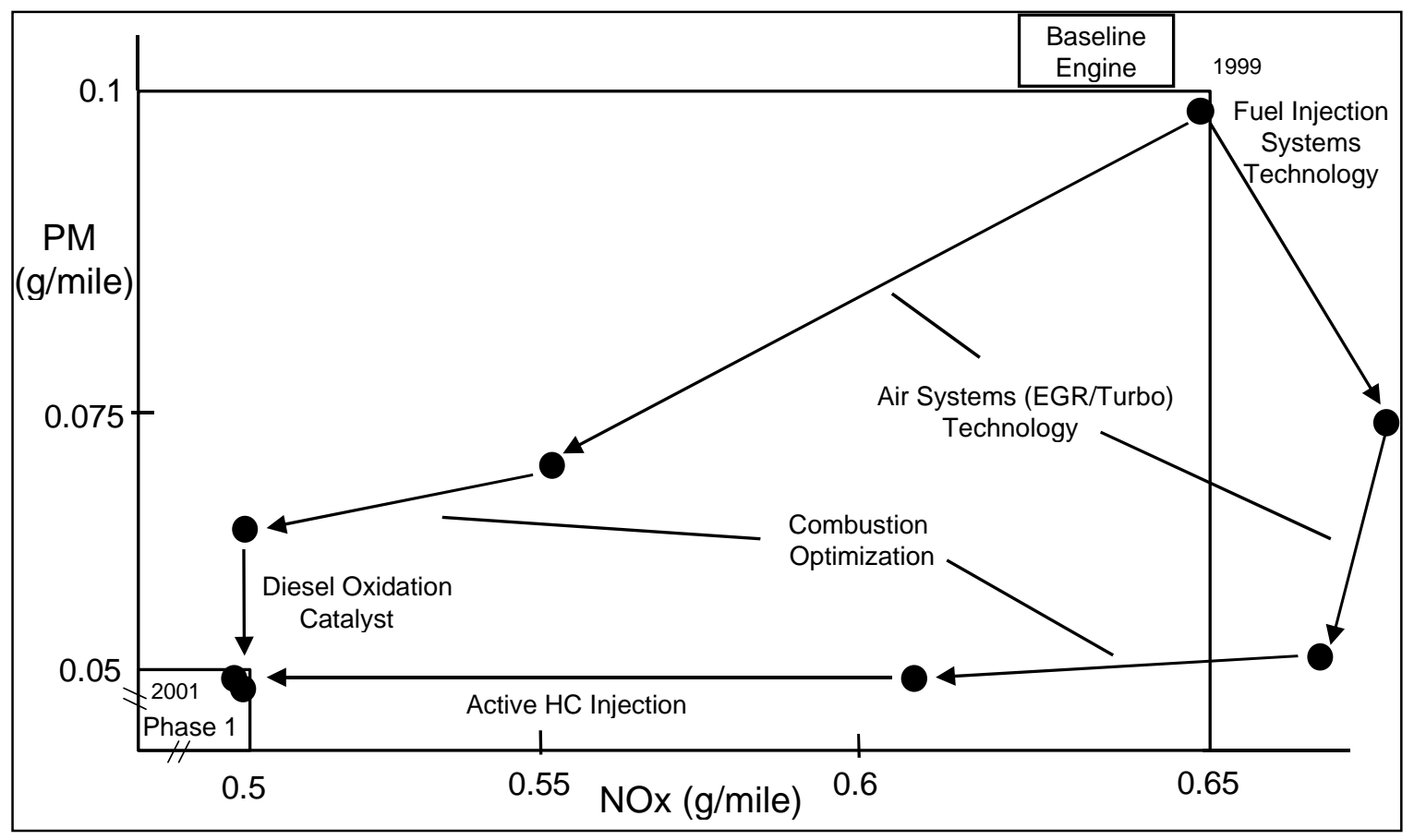

Figure 7. Phase 1 Emissions Program

TASK 1.2 - ENABLING TECHNOLOGY DEVELOPMENT This task included work to design, develop, and evaluate technologies to meet goals identified in Task 1.1. Required areas of development include the fuel system, combustion system, turbocharger/air system, aftertreatment, and control systems. Testing will be completed on current mule engines and/or benches, supplemented with simulation tools where appropriate, to sufficiently evaluate a technology's performance against its goals as established in Task 1.1. Further evaluation of a number of these technologies will be conducted on the HSDI platform engine in Task 1.4.

The revised LTCD program calls for a two-phase emissions program. The difficulty of achieving these goals in a vehicle with a $\sim 5000 \mathrm{lb}$. test weight was recognized from the outset. However, the stringent targets were expected to drive emissions and aftertreatment technology development as applied to HSDI diesel engines to new levels. To guide this development, emission reduction road maps were created to outline the strategy to reach to Phase 1 and Phase 2 targets.

Figure 7 presents a schematic showing the major general elements of the Phase 1 program. The baseline engine is the HSDI V6 platform engine (version A) operating with an oxidation catalyst. FTP-75 emissions data were obtained in a test vehicle at Light Truck/SUV road load conditions. The cycle NOx and particulate emissions were estimated to be $0.65 \mathrm{~g} / \mathrm{mile}$ and $0.1 \mathrm{~g} / \mathrm{mile}$, respectively, taking into account the actual F150 vehicle weight. The represents the starting emission levels for the LTCD Program.
The first major emissions reduction technology to be developed is in the area of fuel injection systems. The Caterpillar HEUI-B fuel system will be implemented in the LTCD engine at an early stage. This fuel system offers cam-independent flexible injection control (small pilot quantities, split injections, adjustable front-end rates, etc.) that will provide approximately $20 \%$ lower particulate emissions levels than the existing VP-44 fuel system. The design for the HEUI-B fuel system for the HSDI platform has been finalized.

Air systems technology development is also a strong emphasis of the Caterpillar LTCD Program. A key enabling technology for future light duty diesel engine emissions compliance is a robust, fast-acting, electronically-controlled exhaust gas recirculation (EGR) system. An EGR team has been formed with representatives from Caterpillar, Perkins and Arthur D. Little to develop this system. [6] The system specifications for a light duty diesel engine are driven by the need for EGR at speed and load conditions that are determined by the emissions and drive cycle requirements. For engines with one or more EGR valves and a variable geometry turbocharger, control of airflow and pressure to deliver precise amounts of EGR to the manifold is a challenging task. The team's approach is to use model-based control (MBC) with appropriate sensors and actuators to accomplish EGR system control.

Model-based control offers benefits of reduced engine calibration time as well as enabling a system with faster response time. Transient air/fuel ratio control is seen as a key to achieving compliance with EURO 4 and US Federal Tier 2 NOx and particulate emissions goals. A key component to maintaining minimal air/fuel ratio 
excursion from a target value over engine transients is the ability to modulate EGR in a rapid manner. When an EGR system is used, the response time of the EGR valve(s) during transient operations must be fast enough to prevent starving the cylinder of oxygen (which can lead to large particulate increases).

Several different EGR valve actuators have been evaluated through bench testing to determine their response times (opening and closing) to various driving voltages. The measured responses can be used in the model-based control algorithm development to more accurately represent the total system response time. The tighter transient Air/Fuel Ratio (AFR) control of the EGR system has been estimated to reduce particulates by approximately $25 \%$ with a further $5-15 \%$ reduction in NOx emissions levels.

Combustion optimization techniques (bowl/swirl/fuel spray matching) using Computational Fluid Dynamics (CFD) to guide an experimental test program should lead to further $10 \%$ reductions in NOx and PM.

Depending upon which Phase 1 path is chosen (Figure 7), a more conventional aftertreatment technology will then be required to achieve the emissions targets. The first option is an active lean NOx catalyst with supplemental hydrocarbon (HC) injection. NOx conversion efficiencies of $30 \%$ with this type of system have been advertised by several major catalyst Original Equipment Manufacturers (OEMs). However, an FTP-75 cycle conversion efficiency of $18 \%$ should be adequate to achieve Phase 1 emissions targets, assuming the other systems achieve reductions as indicated. Alternatively, with a different injection timing and EGR tune for NOx control, an advanced Diesel oxidation catalyst capable of
$20 \%$ particulate reduction could be used. Either of these paths requires overall NOx and PM reductions of $23 \%$ and $46 \%$, respectively, compared with the existing baseline engine. This level of reduction will require significant technological advances over the next two years, but is feasible based on existing information.

A schematic showing the major general elements of the Phase 2 program is presented in Figure 8 . The Phase 2 emissions targets mandate substantially improved performance from the fuel and air systems (engine out reductions of $44 \% \mathrm{NOx}$ and $61 \% \mathrm{PM}$ ). In addition, advanced aftertreatment solutions capable of further 70 $85 \%$ reductions in NOx and $\mathrm{PM}$ will be required.

Overall reductions from the baseline engine of approximately $90 \%$ for both NOx and PM will be required to meet the stringent Phase 2 targets.

Collaborative programs between Caterpillar and catalyst OEMs and consulting firms will be required to develop these advanced aftertreatment systems.

Three primary paths have been identified as indicated in Figure 8. The first uses diesel fuel with a regular $(\sim 300$ $\mathrm{ppm}$ ) sulfur level. The technology with the most potential here is a system using a urea-Selective Catalytic Reduction (SCR) system combined with a catalyzed diesel particulate filter. The second path requires ultralow sulfur $(<10 \mathrm{ppm})$ fuel but allows for NOx trap and continuously regenerating trap (CRT) technology. Finally, a third path using alternative technologies has been identified. Here, advanced systems such as a partial oxidation fuel reformer, non-thermal plasma (with catalyst) and homogeneous charge compression ignition combustion could be used as enabling technologies.

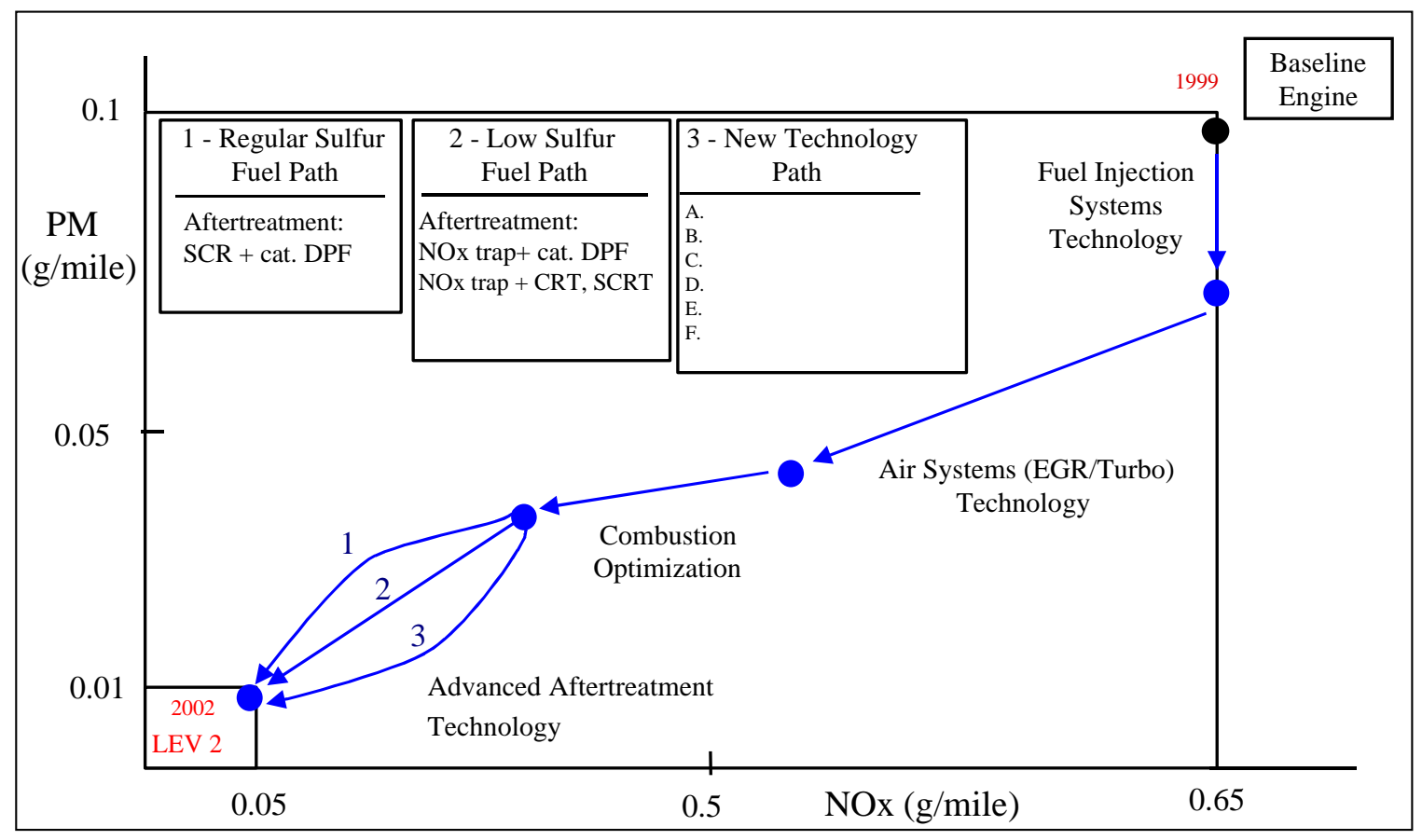

Figure 8. Phase 2 Emissions Program 
Clearly there are numerous inhibitors to implementation of each of these advanced diesel emissions reduction technologies in light truck and sport utility vehicle applications in the future. Foremost are the time, cost, and technology hurdles associated with their development. Lower temperature SCR catalysts and better NOx trap regeneration schemes are being investigated, but must be further developed. Durable/ advanced sensors for urea and NOx must be developed for use in feedback control and anti-defeat applications.

The highly interactive nature between the fuel injection, turbocharger, EGR and aftertreatment systems will mandate improvements in microprocessor speed and controls algorithms. The increasing stringency of the legislated emissions levels makes the task more difficult to achieve. In addition, for several of the aftertreatment technologies, significantly lower fuel sulfur levels will be required to improve catalyst performance and prevent poisoning. Finally, for SCR aftertreatment systems, infrastructure improvements will be needed to support the distribution of urea.

\section{TASK 1.4 - VEHICLE ENGINE DEVELOPMENT - This} task includes all activities related to the development of a HSDI engine system for the full size, prototype vehicle demonstration in Task 1.5. The LTCD team has worked together to design and develop the LTCD engine using the HSDI V-6 engine platform system as the base design. The engine platform has been modified using fuel system and EGR technologies developed in Tasks 1.2.

The LTCD program has three different classes of engines based on the existing platform (A, B, \& $C)$. In this task, a sub-program to design, procure, and test each HSDI version was established. Progress was made on the ' $A$ ' and ' $B$ ' programs. The ' $C$ ' program is scheduled to start late in 1999. The accomplishments of the 'A' and 'B' programs are as follows:

Engine A - The aims of this program were to gain an initial insight into the HSDI engine's frictional characteristics and to exploit any known opportunities for improvement. Three ' $A$ ' engines were built from existing components carried over from the original HSDI development project. Several design modifications were incorporated into the build of the three engines. The most significant was to alter the exhaust manifolds to convert from a twin turbocharger arrangement to a single VGT turbocharger mounted on a bracket at the rear of the engine.

In order to realize competitive fuel economy and a higher power density for the ' $\mathrm{B}$ ' engine (and the eventual ' $\mathrm{C}$ ' engine), it was important to understand the most important sources of friction in the ' $A$ ' engine. Engine tests were run to establish friction using Willans lines. For these tests the engine was built using the single VNT. Results were compared to past experience of the HSDI engine configured with the twin turbocharger arrangement. The following conclusions were derived from the test results:
- Friction of the standard ' $A$ ' engine with twinturbochargers is judged to be relatively low at lower engine speeds but rises sharply with speed.

- Friction reductions are necessary to minimize fuel consumption at higher engine speeds and to maximize power density.

- Power curves for the engine with the single VNT significantly reduces the negative pressure difference across the engine at higher engine speeds. At 4000 rpm, the single VNT enabled a fuel consumption savings of $7 \%$ compared to the base HSDI engine.

- The increase of friction with engine speed suggests sliding friction (pistons and bearings), pumping work, and possibly the water pump and the Bosch VP-44 fuel pump as possible sources.

Additional testing is planned to establish the friction contributions from major engine systems such as auxiliaries, fuel pump, top end, and bottom end by progressive disassembly and motoring friction measurements.

Engine $B$ - The aims of the Engine B program work were to incorporate the Caterpillar HEUI-B fuel system into the HSDI engine platform and to procure the required hardware to build four engines. To accomplish these tasks, detailed discussions were held with the Caterpillar HEUI $^{\text {TM }}$ Product group to establish the most suitable injection system for the HSDI engine. The design feasibility study assessed in particular the scope for incorporating the injector into the existing cylinder head without the need for major re-design and procurement activity.

The major modifications included the following:

- Cylinder head fuel rail and injector bore

- Tappet chest replacing cam cover

- HEUI ${ }^{\mathrm{TM}}$ oil rails and piping

- Drive for HEUI ${ }^{\mathrm{TM}}$ oil pump

- Oil pump upgrade for higher flows required, and revised oil filtration system

- Inlet manifold re-design to clear oil rails

- Provision for electronic sensors to support HEUI ${ }^{T M}$ system

Figure 9 shows the rear view of the 'B' engine design.

Installation of the HEUI ${ }^{\mathrm{TM}}$ fuel system required some modifications to the cylinder head. Fuel to feed each injector has to be supplied via a fuel rail machined from the front of the head. The cylinder head casting was modified to add material to the water jacket to accommodate this. Cross feed and return drillings were also installed between the $1^{\text {st }}$ and $3^{\text {rd }}$ cylinder inlet ports. This was the optimum approach to obtain an engine design with the minimal changes to existing hardware in a short time scale. Relocating the glow plugs will be deferred until the ' $C$ ' design phase. 


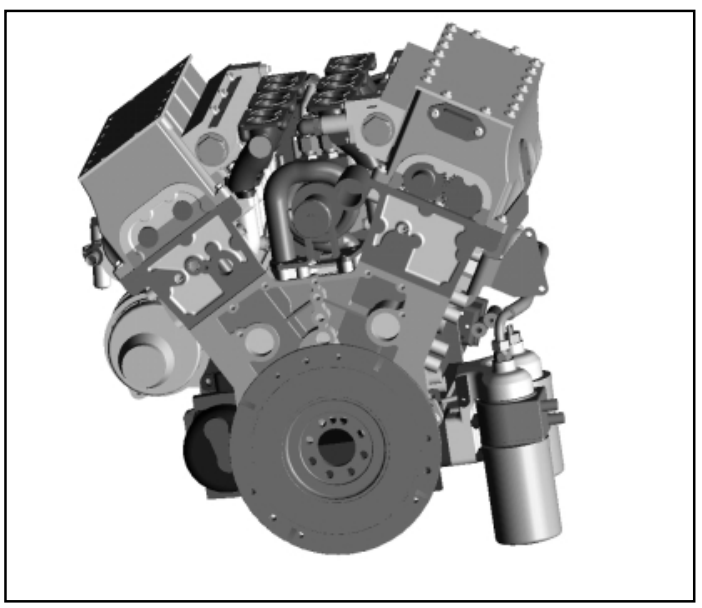

Figure 9. 'B' Engine Rear View

The HEUI ${ }^{T M}$ injectors were installed at the same location of the Bosch injectors. [Figure 10] The injectors were lengthened to minimise engine changes for this phase of the program. Version ' $C$ ' will incorporate standard length injectors.

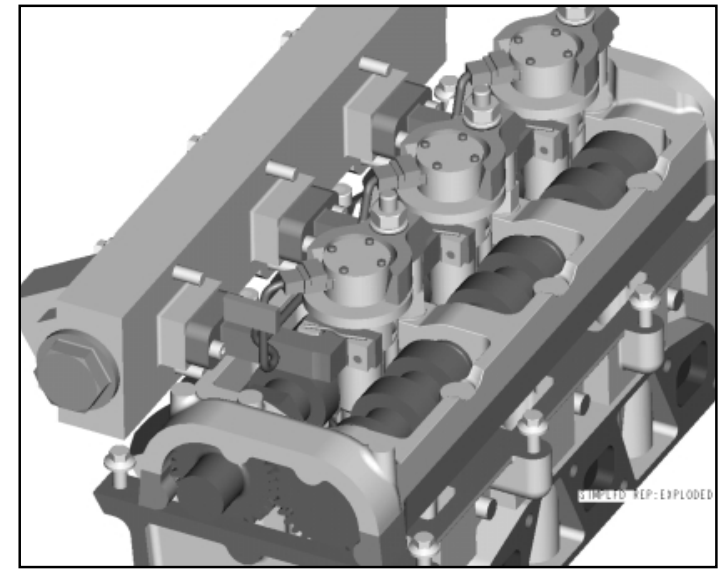

Figure 10. Injector Installation Scheme

The oil required by the injectors is delivered from oil rails mounted on the side of the cast tappet chest via jumper blocks. The oil system components have been stress analysed with internal pressures of 400 bar to withstand a peak pulse pressure of up to 320 bar. The jumper blocks were designed with perpendicular mounting flanges to allow for all tolerance stack-ups.

For the 'B' engine design, the HEUI ${ }^{\mathrm{TM}}$ medium duty oil pump was packaged into the same space as the Bosch VP44 rotary fuel pump on the 'A' engine (Figure 11) and is driven at half engine speed. It was mounted to the rear of the timing case via an adapter.

The medium duty HEUI ${ }^{\mathrm{TM}}$ pump was a significant factor which influenced the design of components within the Vee and resulted in a $80 \mathrm{~mm}$ height increase over the original HSDI 'A' engine. Although this height increase is not a major issue for the Ford F150 vehicle, it would be a concern for vehicles with smaller engine bays. Future pump designs, suitable for light duty applications, will be smaller and provide more freedom to install in optimum locations to reduce impacts on engine height.

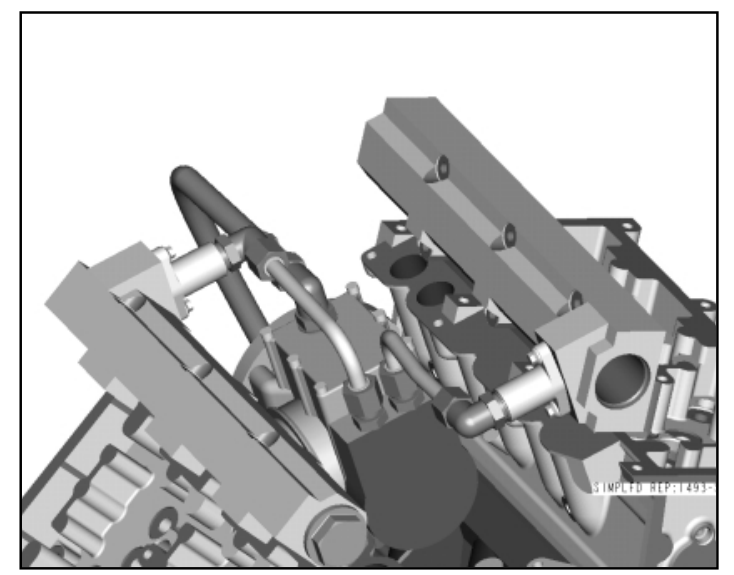

Figure 11. HEUI ${ }^{\mathrm{TM}}$ Pump Installation Scheme

To support the LTCD Program, a development chassis vehicle designed specifically for light duty emissions and vehicle driveability development will be built. After evaluating options, the LTCD team decided to utilize a American Race Truck (ART) F-150 (Figure 12) as the development chassis. This vehicle was chosen because it offered the lowest cost, most flexible platform for vehicle system development. Sensors, actuators, ECU, monitoring and data acquisition systems together with their associated harnesses are mounted in such a way to allow easy access, modification, calibration, and servicing.

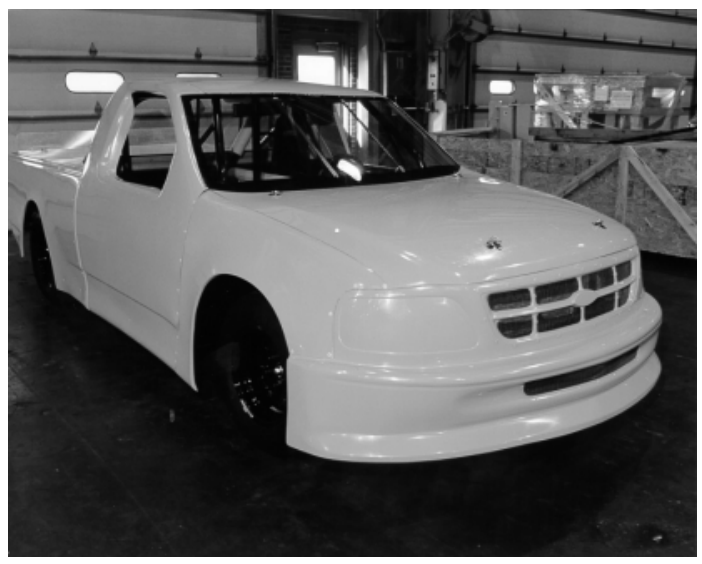

Figure 12. ART F150 Emission Test Chassis

Initial installation will utilize a HSDI 'A' engine (and subsequently the 'B' and ' $\mathrm{C}$ ' versions) with full instrumentation including sensors/actuators, ECU, and a 64 channel Data Acquisition System (DAS) system. The F-150 ART chassis (Figure 13) and transmission hardware have been procured. Figure 13 shows a closeup view of the chassis with panels removed and the HSDI ' $A$ ' engine located within the engine bay.

Current plans are to build four HSDI 'B' engines and subject to shakedown testing. Subsequently, Engine \#1 will be tested in a steady state cell to develop an initial 
match for the fuel injection and combustion systems. A design of experiments has been developed to optimise the swirl level, piston bowl, and injector nozzle tip design. After a first tune is developed, the engine would be transferred to an emissions chassis for tuning over the FTP-75 transient test cycle. Engine \#2 will be installed in a separate steady state test cell and will be dedicated for fuel system rate shaping development. Engine \#3 will be installed in the F150 to produce a vehicle demonstrator suitable for initial performance, driveability, and $\mathrm{NVH}$ assessment. Engine \#4 will serve as the spare.

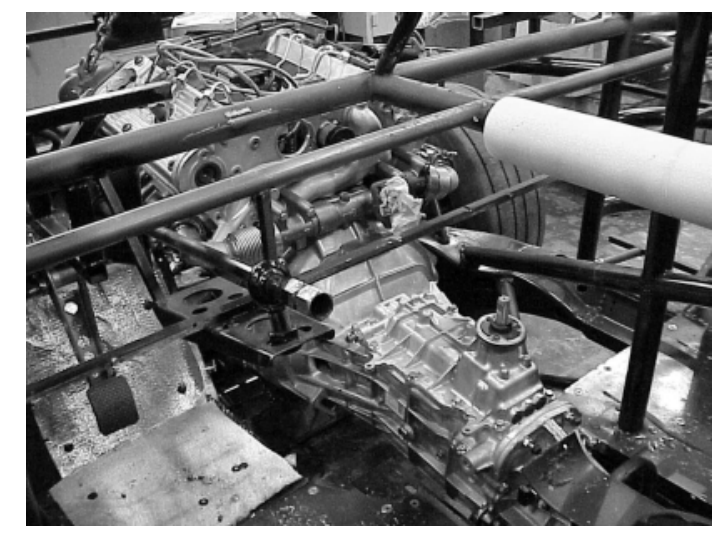

Figure 13. Emissions Chassis with ' $A$ ' Engine

\section{SUMMARY AND CONCLUSIONS}

DOE's light truck program offers significant challenges but also has the potential to bring tremendous value through large reductions in fuel usage in the light truck vehicle market and through significant reductions in one of the primary greenhouse gases $\mathrm{CO}_{2}$. The diesel engine powerplant offers the greatest potential for meeting the program fuel economy goals in the shortest amount of time. Meeting Tier 2 emissions requirements, while still maintaining a significant fuel economy advantage and a low system cost, will be the significant challenge and will required the latest diesel engine technologies.

U.S. diesel engine manufacturers have continuously improved the emissions and performance of their products over the past 20 years, reducing regulated NOx emissions by 70 percent and lowering particulate emissions by 90 percent. During that same period, diesel engine fuel efficiency has improved over 25 percent. These same, and even more advanced, technologies when incorporated into light duty platforms will result in products that meet customer expectations and provide significant value to the consumer.

The Caterpillar LTCD program is developing CIDI technology using a V-6 HSDI engine as the base platform. Emphasis is being placed on developing industry leading fuel system, EGR, and aftertreatment enabling technologies for subsequent application to the Base platform. The result of this development will be applied to a 1999 Ford F150 SuperCab light truck vehicle. The LTCD vehicle is expected to demonstrate $50 \%$ improved fuel economy when compared to a 1998
F150 base vehicle while meeting the Tier II emission regulations.

\section{ACKNOWLEDGEMENTS}

This work was performed under the Department of Energy Cooperative Agreement DE-FC05-97OR22605 "Cooperative Development of Technologies for a High Efficiency, Very Low Emission, Diesel Engine for Light Trucks and Sport Utility Vehicles". The authors would like to thank the members of the Caterpillar LTCD program management team including Bill Siegel (DOE), John Fairbanks (DOE), Mary Rawlins (DOE-Oak Ridge), Rich Belaire (Ford Motor Company), Jim Sibley (Caterpillar) and Jeri Cripe (Caterpillar) for their continued support of this work and also Bruce Bannister, Carlo Bovenzi, Martin Parsons, lan Middlemiss, Richard Cresswell and John Crosse of Perkins Technology for their technical and project support.

\section{REFERENCES}

1. Department of Energy, Multi-Year Program Plan for 1998-2002, Office of Heavy Vehicle Technologies and Heavy Vehicle Industry Partners, August 1998, page 23.

2. www.autofacts.com/free/ne9901A1.htm

3. www.fordvehicle.com/fseries

4. Southall, R. and Trimm, M. "Noise and Vibration Technology for the Perkins V6 HSDI Demonstration Engine," SAE Paper 972044, 1997.

5. www.becker-associates.com/gfdwhatis.htm

6. Duffy, K., Miller, R., Bowyer, R., Bromnick, P., Mason, P., Stobart, R., Wilson, R., Middlemiss, I., Parsons, M.: "Model-Based EGR Control Development for an HSDI Engine", ASME Paper 99-ICE-203, Proceedings of ASME ICE FC, Internal Combustion Engine 1999 Fall Conference, Oct. 16-20, 1999, Ann Arbor, MI

\section{APPENDIX}

\section{QFD DEFINITIONS- CUSTOMER WANTS}

\section{Driveability}

Encompasses all elements of how the vehicle performs as a transportation or utility vehicle for the customer. Includes handling, response, acceleration rate, deceleration rate, braking, steering, smoothness, towing, climbing and many less definable characteristics such as those typically rated via a user panel. Assessed during all operating conditions and in all operating environments.

\section{NVH}

Characteristics of the vehicle and engine noise, vibration and harshness occurring during all phases of operation and in all environmental conditions. Includes air born noise at the vehicles exterior and noise within the closed 
vehicle environment. Specific noise and vibration and levels and frequency characteristics can be measured. The more subjective harshness or noise quality characteristics can frequently be measured and are many times assessed through a jury panel review of the vehicle.

\section{Transparency}

Reflects the vehicle's performance and characteristics relative to a gasoline automobile. Includes parameters such as convenience, user friendliness, price, smell, esthetics, operational limitations, on-board diagnostics (OBD) compliance and serviceability.

\section{$50 \%$ Mileage}

The goal of the program which is to achieve a $50 \%$ tank mileage improvement over the equivalent 1997 gasoline powered vehicles. This performance parameter is to be evaluated on a vehicle basis and will be measured during various operational cycles.

\section{Emissions}

Reflects compliance with the program's established phase I and phase II gaseous emissions goals.

\section{Installation}

The ability of the powertrain to operate in the specified target vehicle without major modifications to the basic structure and operation of the vehicle. Powertrain is defined as the engine, transmission, axles, differential, wheels and tires, and ancillary devices.

\section{Reliability}

The ability of the vehicle and powertrain to perform its anticipated function to the user's satisfaction for a specified period of time. Durability (longer term wear-out) is considered to be a subset of reliability.

\section{Image}

Includes the customer perceived image of both the vehicle and powertrain and the technological images of Caterpillar, Perkins and Ford. Reflects the view of Perkins and Caterpillar as high technology companies that offer service to both internal and external customers because of the technological capabilities.

\section{Timing}

Reflects meeting the stated timing objectives of the program plus the timeliness of an HSDI product delivered to the marketplace.

\section{Production}

Reflects the viability of the product delivered through this program in terms of product cost, technological feasibility, capital expense requirements, qualified suppliers (internal \& external) and readiness for production.

\section{Technology Development}

The ability to utilize and extend the current technological capabilities within the companies and the opportunity to define and develop new technologies beneficial to all of Caterpillar and potentially to others in the powertrain development industry.

\section{Manufacturing}

The development of advanced manufacturing expertise including materials and processes used in the manufacture, assembly and delivery of advanced CIDI engines. 